\title{
4D Multiphase steady state imaging with contrast (MUSIC) enhancement using ferumoxytol: a new paradigm in pediatric congenital heart disease
}

Kim-Lien Nguyen ${ }^{1,2^{*}}$, Fei Han ${ }^{1}$, Daniel Z Brunengraber ${ }^{1}$, Stanislas Rapacchi ${ }^{1}$, Ihab Ayad ${ }^{3}$, Gary M Satou ${ }^{4}$, Peng Hu', J Paul Finn ${ }^{1}$

From 19th Annual SCMR Scientific Sessions

Los Angeles, CA, USA. 27-30 January 2016

\section{Background}

CMR in children with congenital heart disease (CHD) often requires expert physician supervision and long examination times. Further, the complex anatomy may not be fully defined with limited 2D slices at the time of image acquisition and missing slice orientations cannot be reconstructed retrospectively. 4D MUSIC (1) generates isotropic high-resolution 3D images over multiple, independent cardiac phases without breath holding. We aim to evaluate this technique in patients with complex $\mathrm{CHD}$ and compare it to breathe held contrast enhanced MRA (CE-MRA) and 2D cine.

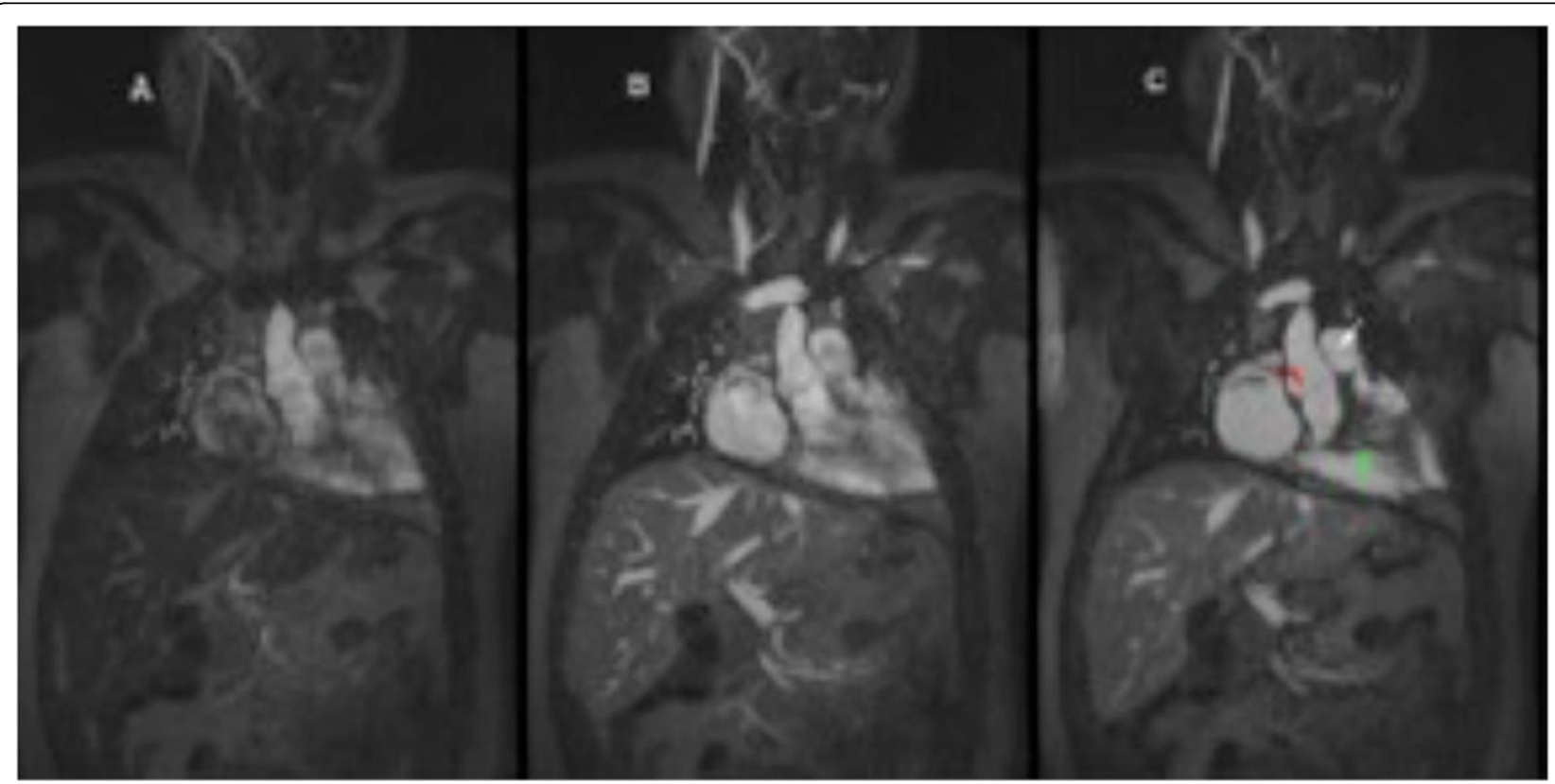

Figure $1(a, b, c)$. Breath held first pass (A), breath held steady state (B) and MUSIC (C) images in an 18 y.o. female with repaired Tetralogy of Fallot. The arrows point to well defined aortic (red) and pulmonary (white) valve leaflets as well as thickened right ventricular trabeculae (green).

'Department of Radiological Sciences, David Geffen School of Medicine at

UCLA, Los Angeles, CA, USA

Full list of author information is available at the end of the article

(0) 2016 Nguyen et al. This is an Open Access article distributed under the terms of the Creative Commons Attribution License (http:// original work is properly cited. The Creative Commons Public Domain Dedication waiver (http://creativecommons.org/publicdomain/ zero/1.0/) applies to the data made available in this article, unless otherwise stated. 


\section{Methods}

Forty-three children (age 3 days to 19 years; weight $1.2 \mathrm{~kg}$ to $62 \mathrm{~kg}$ ) with suspected or known complex CHD underwent ferumoxytol-enhanced CMR on a 3.0T MRI system between 2013 and 2015. Two readers with advanced CMR training scored the diagnostic image quality of named intra-cardiac structures and multiple vascular segments including the coronary arteries using a four-point scale. Surgery, correlative imaging or autopsy confirmed MUSIC MRI findings. Quantitative volumetric measurements derived from 4D MUSIC and conventional 2D cine images were compared.

\section{Results}

There were no adverse reactions to ferumoxytol. Intracardiac and vascular anatomy were significantly better visualized ( $\mathrm{p}<0.001)$ with MUSIC than with breath held CE-MRA. Coronary artery anatomy was routinely visualized with high confidence on MUSIC images. Quantitative volumetric measurements derived from 4D MUSIC and conventional $2 \mathrm{D}$ cine imaging were strongly correlated $(\mathrm{r}=0.99, \mathrm{p}<0.001)$ and concordance with correlative imaging, surgical findings and /or autopsy results was excellent.

\section{Conclusions}

Ferumoxytol-enhanced 4D MUSIC is superior to breathheld CEMRA in children with CHD and may serve as a comprehensive technique for high resolution anatomic and dynamic imaging. The implications for safe and rapid streamlining of data acquisition in pediatric CHD, and for diagnostic evaluation of patients too unstable for breath holding are significant.

\section{Authors' details}

'Department of Radiological Sciences, David Geffen School of Medicine at UCLA, Los Angeles, CA, USA. ²Division of Cardiology, David Geffen School of Medicine at UCLA and VA Greater Los Angeles Healthcare System, Los Angeles, CA, USA. ${ }^{3}$ Department of Anesthesiology, David Geffen School of Medicine at UCLA, Los Angeles, CA, USA. ${ }^{4}$ Division of Pediatric Cardiology, David Geffen School of Medicine at UCLA, Los Angeles, CA, USA.

Published: 27 January 2016

doi:10.1186/1532-429X-18-S1-0113

Cite this article as: Nguyen et al:: 4D Multiphase steady state imaging with contrast (MUSIC) enhancement using ferumoxytol: a new paradigm in pediatric congenital heart disease. Journal of Cardiovascular Magnetic Resonance 2016 18(Suppl 1):0113.

\section{Submit your next manuscript to BioMed Central} and take full advantage of:

- Convenient online submission

- Thorough peer review

- No space constraints or color figure charges

- Immediate publication on acceptance

- Inclusion in PubMed, CAS, Scopus and Google Scholar

- Research which is freely available for redistribution

Submit your manuscript at www.biomedcentral.com/submit
C BioMed Central 